\title{
Comparison of Feeding Jejunostomy via Gastric Tube Versus Jejunum After Esophageal Cancer Surgery
}

\author{
TOMOKI KONISHI, ATSUSHI SHIOZAKI, HITOSHI FUJIWARA, HIROTAKA KONISHI, \\ KENICHI TAKEMOTO, MICHIHIRO KUDOU, KATSUTOSHI SHODA, TOMOHIRO ARITA, \\ TOSHIYUKI KOSUGA, RYO MORIMURA, YASUTOSHI MURAYAMA, YOSHIAKI KURIU, HISASHI IKOMA, \\ TAKESHI KUBOTA, MASAYOSHI NAKANISHI, KAZUMA OKAMOTO and EIGO OTSUJI
}

Division of Digestive Surgery, Department of Surgery, Kyoto Prefectural University of Medicine, Kyoto, Japan

\begin{abstract}
Background: Jejunostomy is an essential route for nutritional support after esophageal cancer surgery. However, catheter-related complications may occur. This study compared the complications of feeding jejunostomy between gastric tube and jejunum after esophageal cancer surgery. Patients and Methods: The records of 215 patients with esophageal cancer who underwent radical esophagectomy with retrosternal gastric tube reconstruction between January 2010 and November 2016 were examined. One hundred and thirty-three patients underwent feeding jejunostomy via gastric tube and 82 patients underwent the procedure via the jejunum, and their records were reviewed for catheter-related complications. Results: Catheter-related complications occurred in five patients in the gastric tube group and 12 in the jejunum group $(3.8 \%$ vs. $14.6 \%$, $p=0.005)$. Mechanical bowel obstruction requiring surgical therapy occurred in three patients in the jejunum group, but in none in the gastric tube group $(p=0.026)$. Conclusion: Feeding jejunostomy reconstruction via gastric tube appears to be a safe and useful procedure.
\end{abstract}

In gastrointestinal surgery, jejunostomy is often used for nutritional management following highly invasive surgery after which patients are unlikely to be able to eat for some time. This procedure is very important for patients with esophageal cancer who are often in a poor nutritional state due to hypophagia resulting from esophageal stenosis or preoperative chemotherapy. Early enteral nutrition using

Correspondence to: Dr. Atsushi Shiozaki, Assistant Professor, Division of Digestive Surgery, Department of Surgery, Kyoto Prefectural University of Medicine, 465 Kajii-cho, Kamigyo-ku, Kyoto 602-8566, Japan. Tel: +81 752515527, Fax: +81 752515522, e-mail: shiozaki@koto.kpu-m.ac.jp

Key Words: Jejunostomy, gastric tube, esophageal cancer, reconstruction, feeding. feeding jejunostomy is useful for perioperative management after esophagectomy to improve the nutritional state. Due to these benefits, enteral feeding via jejunostomy is administered from the early postoperative period for almost all patients with esophageal cancer who undergo radical esophageal resection at our Institute. However, catheter-related complications, such as tube site infection, dislocation of the catheter edge, peritonitis and mechanical obstruction, sometimes occur. Mechanical bowel obstruction, in particular, is one of the most serious complications because it often requires reoperation and leads to poor nutrition. A previous report suggested that enteral feeding jejunostomy via a gastric tube can reduce catheter-related complications (1).

We have been employing feeding jejunostomy via gastric tube for its potential efficacy in reducing catheter-related complications since 2010. In this study, we compared feeding jejunostomy via gastric tube with that via the jejunum after esophageal cancer surgery, focusing on catheter-related complications.

\section{Patients and Methods}

Patients. Two hundred and fifteen patients with esophageal cancer underwent radical esophageal cancer surgery and retrosternal gastric tube reconstruction between January 2010 and November 2016 at the Division of Digestive Surgery, Department of Surgery, Kyoto Prefectural University of Medicine. Of these patients, 133 feeding jejunostomy via the gastric tube and 82 patients via the jejunum. The records of all patients were reviewed, and catheter-related complications, such as catheter site infection, dislocation, catheterrelated peritonitis and mechanical obstruction, were analyzed.

Procedure. In both groups, abdominal manipulation was carried out at a median epigastric incision, gastric tubes were created using mechanical stapling devices, and a 9-Fr silicon catheter (Kangaroo Jejunostomy Catheter; Covidien Japan, Tokyo, Japan) was used following the instruction manual. Jejunostomy via gastric tube was from the antrum of the stomach to the pyloric ring and duodenal bulb. While injecting $0.9 \%$ saline into the duodenum through the catheter, it was inserted approximately 30 
$\mathrm{cm}$ to a position beyond the ligament of Treitz and fixed with a purse string suture at the point where the tube penetrated the gastric wall. The catheter was passed through the abdominal wall and was guided to the skin surface untwisted. It was fixed with two sutures between the puncture site and the abdominal wall. The catheter was eventually guided through the right hypochondriac site and fixed to the skin surface.

Jejunostomy via the jejunum was through the upper jejunum at approximately $30 \mathrm{~cm}$ from the ligament of Treitz. While injecting $0.9 \%$ saline into the duodenum through the catheter, the catheter was inserted and fixed with a purse string suture at the point of insertion. The catheter was passed through the abdominal wall and was guided to the skin surface naturally. It was fixed with two sutures between the puncture site and the abdominal wall. The catheter was eventually guided through the left hypochondriac site and fixed to the skin surface (Figure 1).

Nutritional support and fluid management. Nutritional support and fluid management during the perioperative phase was not standardized. After surgery, enteral feeding was started on postoperative day (POD) 1 using a continuous 24-h infusion of immunoenhancing enteral nutrients, beginning with $10 \mathrm{ml} / \mathrm{h}$ on POD 1 and progressing to the maximum volume of $60-80 \mathrm{ml} / \mathrm{h}$ by POD 7 , paying attention to diarrhea. Intravenous infusion via the central vein was usually given at $1,500-2,000 \mathrm{ml} /$ day and was gradually reduced as enteral feeding increased until oral intake was started. Oral intake was generally allowed on POD 7 after confirming the absence of anastomotic leakage and aspiration by videofluoroscopic examination of swallowing. Enteral feeding was gradually reduced as the oral intake increased, and continued until oral intake stabilized. The timing of catheter removal was not normalized and was at the doctor's consideration of sufficient oral intake. In some cases, patients were discharged without removal of the catheter.

Statistical analysis. Data in our computerized database were examined in this retrospective study. Additional data were obtained by reviewing the medical records. Patient demographic data, incidence of complications that may lead to re-laparotomy, including mechanical obstruction, catheter site infection, catheterrelated peritonitis, and dislodging of the catheter due to indwelled catheter, and other complications were evaluated. Clinical staging of tumors was performed according to the tumor-node-metastasis (TNM) classification system (2). All analyses were performed using JMP software (version 12; SAS Institute Inc., Cary, NC, USA). All continuous variables are presented as the mean \pm standard deviation. All data were compared using the chi-square test to evaluate differences between qualitative variables. A $p$-value of less than 0.05 was considered significant.

\section{Results}

Clinicopathological features. Patient and tumor characteristics are listed in Table I. There was no significant difference between groups regarding variables such as gender, age, body mass index, tumor location, $\mathrm{pT}, \mathrm{pN}$, and pStage. The mean age of the patients was $66.9 \pm 9.2$ years in the gastric tube group and $65.4 \pm 8.7$ years old in the jejunum group. The tumor depth was pT0-1 in 94 patients (43.7\%), T2-3 in 121 (56.3\%), N0 lymph node metastasis in 98 (45.6\%), and N1-3 in 117
(54.4\%). Pathological staging was pStage 0 in 27 (12.6\%), pStage I in 43 (20.0\%), pStage II in 63 (29.3\%), pStage III in 65 (30.2\%), and pStage IV in 17 (7.9\%).

Postoperative complications. Catheter-related complications are shown in Table II. Five patients (3.8\%) in the gastric tube group and $12(14.6 \%)$ in the jejunum group developed complications $(p=0.005)$. Details of catheter-related complications, such as the catheter falling out of the intestinal tract, displacement, catheter site infection, catheter kinking, and mechanical bowel obstruction, were confirmed. No patients in the gastric tube group had mechanical bowel obstruction, whereas three patients $(3.7 \%)$ in the jejunum group did $(p=0.026)$. All three required surgery and one patient underwent bowel resection due to strangulated mechanical obstruction. There were no complications requiring surgery in the gastric tube group. Diarrhea was less frequent in the gastric tube group $(11.2 \%$ vs. $24.3 \%$, $p=0.007)$. The mean postoperative hospital stay was $40.4 \pm 22.3$ days for the gastric tube group and 59.0 \pm 48.4 days for the jejunum group $(p<0.001)$. Almost all complications were improved by withdrawing and exchanging the catheter, but mechanical bowel obstruction required surgery. The hospital stay was longer for those with complications, especially for patients with mechanical bowel obstruction requiring surgery (Table III).

\section{Discussion}

Following highly invasive gastrointestinal surgery, enteral nutrition is used for nutritional management. This is particularly important for patients who cannot start oral intake for some time after esophagectomy. Appropriate nutritional management promotes wound healing, and reduces the complication and mortality rates, hospital stay, and medical expenses (3). In patients with esophageal cancer, early enteral nutrition using feeding jejunostomy may reduce the duration of intensive care unit treatment and enhance recovery of the immune system (4). However, jejunostomy has disadvantages, such as mechanical complications, including tube blockage, site infection and bowel obstruction, and functional complications, including diarrhea, vomiting and hyperglycemia (5). In this study, one of the most frequent functional complications was diarrhea. Although patients in the jejunum group developed diarrhea more frequently than those in the gastric-tube group, severe cases were not observed and almost all patients recovered with dose reduction of enteral nutrition or drugs to control intestinal function. Therefore, we focused on mechanical complications that may become severe. Srinathan et al. reported six patients (5.4\%) who developed complications due to the jejunostomy tube in a study of 111 patients following esophagectomy; three patients (2.7\%) with 


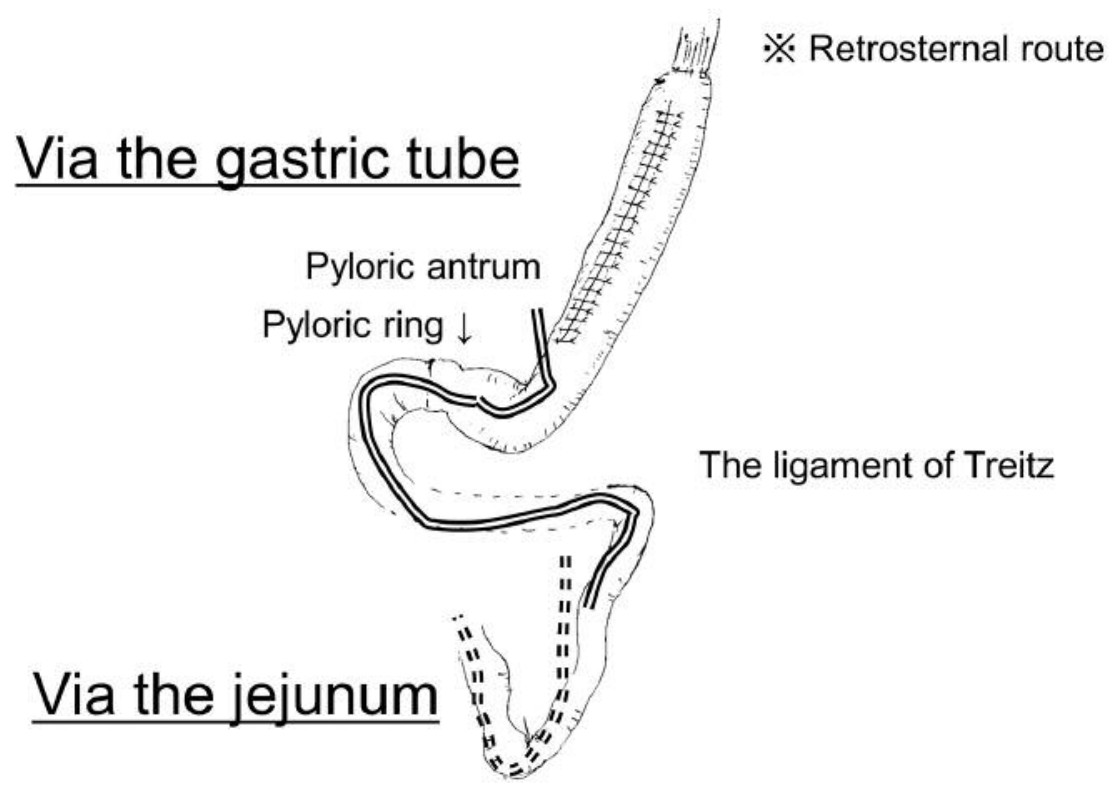

Figure 1. Abdominal manipulation was carried out at a median epigastric incision, the gastric tube was created using mechanical stapling devices, and a 9-Fr silicon catheter (Kangaroo Jejunostomy Catheter; Covidien Japan, Tokyo, Japan) was implanted via the gastric tube or jejunum following the instruction manual.

Table I. Patient demographics and clinical characteristics.

\begin{tabular}{|c|c|c|c|}
\hline \multirow[b]{2}{*}{ Characteristic } & \multicolumn{2}{|c|}{ Jejunostomy } & \multirow[b]{2}{*}{$p$-Value } \\
\hline & $\begin{array}{c}\text { Gastric tube } \\
\quad(\mathrm{n}=133)\end{array}$ & $\begin{array}{c}\text { Jejunum } \\
(\mathrm{n}=82)\end{array}$ & \\
\hline \multicolumn{4}{|l|}{ Gender } \\
\hline Male & 112 & 68 & 0.804 \\
\hline Female & 21 & 14 & \\
\hline \multicolumn{4}{|l|}{ Age } \\
\hline$\leq 65$ Years & 85 & 46 & 0.254 \\
\hline$>65$ Years & 48 & 36 & \\
\hline \multicolumn{4}{|l|}{ BMI $\left(\mathrm{kg} / \mathrm{m}^{2}\right)$} \\
\hline Mean \pm SD & $21.3 \pm 3.1$ & $20.8 \pm 2.8$ & 0.299 \\
\hline \multicolumn{4}{|l|}{ Tumor location } \\
\hline $\mathrm{Ce} / \mathrm{Ut}$ & 29 & 18 & 0.999 \\
\hline Mt & 68 & 42 & \\
\hline $\mathrm{Lt} / \mathrm{Ae}$ & 36 & 22 & \\
\hline \multicolumn{4}{|l|}{ pT } \\
\hline T0-1 & 58 & 26 & 0.966 \\
\hline $\mathrm{T} 2-4$ & 75 & 46 & \\
\hline \multicolumn{4}{|l|}{$\mathrm{pN}$} \\
\hline NO & 64 & 34 & 0.341 \\
\hline N1-3 & 69 & 48 & \\
\hline \multicolumn{4}{|l|}{ TNM pStage } \\
\hline pStage 0-I & 42 & 24 & 0.344 \\
\hline pStage II-IV & 73 & 56 & \\
\hline
\end{tabular}

BMI: Body mass index, SD: standard deviation, Ce: cervical esophagus, Ut: upper esophagus, Mt: middle thoracic esophagus, Lt: lower esophagus, Ae: abdominal esophagus, pT: pathological T stage, $\mathrm{pN}$ : pathological N stage.
Table II. Postoperative complications and outcome.

\begin{tabular}{|c|c|c|c|}
\hline & \multicolumn{2}{|c|}{ Jejunostomy } & \multirow[b]{2}{*}{$p$-Value } \\
\hline & $\begin{array}{l}\text { Gastric tube } \\
\quad(n=133)\end{array}$ & $\begin{array}{l}\text { Jejunum } \\
(\mathrm{n}=82)\end{array}$ & \\
\hline Catheter-related complications & $5(3.8 \%)$ & $12(14.6 \%)$ & 0.005 \\
\hline Catheter falling out & 2 & 4 & 0.145 \\
\hline Displacement & 3 & 0 & 0.171 \\
\hline Catheter site infection & 0 & 4 & 0.010 \\
\hline Kinking & 0 & 1 & 0.202 \\
\hline Ileus & 0 & 3 & 0.026 \\
\hline Re-operation & $0(0.0 \%)$ & $3(3.7 \%)$ & 0.026 \\
\hline Diarrhea & $15(11.3 \%)$ & $20(24.4 \%)$ & 0.007 \\
\hline Oral intake (days) & $17.5 \pm 11.4$ & $24.0 \pm 30.0$ & 0.072 \\
\hline Tube removal period (days) & $32.3 \pm 12.8$ & $41.4 \pm 45.0$ & 0.054 \\
\hline Hospital stay after surgery (days) & $40.4 \pm 22.3$ & $59.0 \pm 48.4$ & $<0.001$ \\
\hline
\end{tabular}

Data are means \pm SD. Significant $p$-values $(p<0.05)$ are shown in bold (Chi-square test).

complications required surgery (6). In this study, catheterrelated complications occurred more frequently in the jejunum group (14.6\%) than in the gastric tube group (3.8\%).

Jejunostomy via gastric tube does not differ in surgical technique from conventional jejunostomy via the jejunum. A catheter was inserted through the pyloric ring and fixed to the antrum of the stomach and abdominal wall in the gastric tube 
Table III. Details of catheter-related complications in study patients.

\begin{tabular}{lcccc}
\hline Jejunostomy & After operation (days) & Complication & Treatment & Hospital stay (days) \\
\hline Jejunum & 12 & Catheter fell out & Tube removed & 24 \\
Jejunum & 14 & Catheter fell out & Tube removed & 85 \\
Jejunum & 21 & Catheter fell out & Tube exchanged & 61 \\
Jejunum & 9 & Catheter fell out & Tube exchanged & 49 \\
Jejunum & 39 & Catheter site infection & Tube removed & 69 \\
Jejunum & 52 & Catheter site infection & Tube removed & 107 \\
Jejunum & 11 & Catheter site infection & Tube removed & 22 \\
Jejunum & 12 & Catheter site infection & Tube removed & 23 \\
Jejunum & 4 & Kinking & Tube exchanged & 68 \\
Jejunum & 3 & Mechanical obstruction & Surgery & 280 \\
Jejunum & 55 & Mechanical obstruction & Surgery & 177 \\
Jejunum & 263 & Mechanical obstruction & Surgery & 74 \\
Gastric tube & 36 & Catheter fell out & Tube exchanged & 66 \\
Gastric tube & 5 & Catheter fell out & Tube exchanged & 71 \\
Gastric tube & 1 & Displacement & Tube exchanged & 42 \\
Gastric tube & 1 & Displacement & Tube exchanged & \\
Gastric tube & 1 & Displacement & Tube exchanged & 31 \\
\hline
\end{tabular}

group, whereas it was inserted into the small intestine with high mobility and fixed to the abdominal wall in the jejunum group. This is considered to cause twisting and kinking. Several authors reported that jejunal attachment to the parietal peritoneum may cause mechanical bowel obstruction at the catheter insertion site $(7,8)$. As a new method to reduce complications, Oya et al. and Kawai et al. $(1,7)$ reported the usefulness of feeding duodenostomy using the round ligament of the liver. They reported that no mechanical bowel obstruction was observed in patients with feeding duodenostomy, whereas it was observed in $3.7-4.5 \%$ of patients with feeding jejunostomy. The incidence of catheter site infection was also lower in patients with duodenostomy than in those with jejunostomy $(0.9 \%$ vs. $5.2 \%, 0.5 \%$ vs. $5.1 \%)$. Their results clearly demonstrate that duodenostomy via the round ligament of the liver prevents mechanical bowel obstruction and catheter site infection. Our method is similar to this procedure, except we did not use the round ligament of the liver, and we noted no mechanical bowel obstruction or catheter site infection in patients with feeding jejunostomy via the gastric tube, whereas these complications were observed in $4.9 \%$ and $3.7 \%$ of patients with feeding jejunostomy via the jejunum. Our results were consistent with previous reports; therefore, this procedure can reduce the incidence of serious postoperative complications. Although there are reports that have summarized all reconstruction routes (retrosternal, anterior-sternal and posterior mediastinal) after esophagectomy $(1,7)$, to our knowledge, this study is the first to investigate jejunostomy via gastric tube focusing on the retrosternal route.

There were several limitations to our study. Firstly, this was a retrospective observational study. There is a time- related bias because surgical techniques have improved. Thoracotomy and jejunostomy accounted for the majority of procedures during the first half of the analysis period, whereas surgery with non-thoracotomy and gastrostomy accounted for the majority during the second half. Secondly, although catheter-related complications occurred 9 months after surgery in some patients, not all patients can be observed long-term. Thirdly, postoperative nutritional protocols were not standardized and were at the discretion of the attending physician.

Although there exist some limitations, jejunostomy via gastric tube is considered to be a useful enteral feeding route because no disadvantages regarding the procedure or postoperative complications were noted in the group treated this way. In summary, we compared feeding jejunostomy via gastric tube and via the jejunum after esophageal cancer surgery, focusing on catheter-related complications. As a result, jejunostomy via gastric tube is a safe and effective procedure for patients following esophagectomy due to the reduced incidence of postoperative complications.

\section{Conflicts of Interest}

The Authors declare that they have no conflict of interest in regard to this study.

\section{References}

1 Oya H, Koike M, Iwata N, Kobayashi D, Torii K, Niwa Y, Kanda M, Tanaka C, Yamada S, Fujii T, Nakayama G, Sugimoto H, Nomoto S, Fujiwara M and Kodera Y: Feeding duodenostomy decreases the incidence of mechanical obstruction after radical esophageal cancer surgery. World J Surg 39: 1105-1110, 2015. 
2 Brierley JD, Gospodarowicz MK and Wittekind C: International Union Against Cancer (UICC) TNM Classification of Malignant Tumors, 8th Edition. Wiley, New York, 2017.

3 Aiko S, Yoshizumi Y, Sugiura Y, Matsuyama T, Naito Y, Matsuzaki $\mathbf{J}$ and Maehara T: Beneficial effects of immediate enteral nutrition after esophageal cancer surgery. Surg Today 31 : 971-978, 2001.

4 Gabor S, Renner H, Matzi V, Ratzenhofer B, Lindenmann J, Sankin O, Pinter H, Maier A, Smolle J and Smolle-Juttner FM: Early enteral feeding compared with parenteral nutrition after oesophageal or oesophagogastric resection and reconstruction. Br J Nutr 93: 509-513, 2005.

5 Blumenstein I, Shastri YM and Stein J: Gastroenteric tube feeding: techniques, problems and solutions. World $\mathrm{J}$ Gastroenterol 20(26): 8505-8524, 2014.

6 Srinathan SK, Hamin T, Walter S, Tan AL, Unruh HW and Guyatt G: Jejunostomy tube feeding in patients undergoing esophagectomy. Can J Surg 56: 409-414, 2013.
7 Kawai R, Abe T, Uemura N, Fukaya M, Saito T, Komori K, Yokoyama Y, Nagino M, Shinoda M and Shimizu Y: Feeding catheter gastrostomy with the round ligament of the liver prevents mechanical bowel obstruction after esophagectomy. Dis Esophagus 30(6): 1-8, 2017.

8 Yagi M, Hashimoto T, Nezuka H, Ito H, Tani T, Shimizu K and Miwa K: Complications associated with enteral nutrition using catheter jejunostomy after esophagectomy. Surg Today 29: 214$218,1999$.
Received June 14, 2018

Revised June 26, 2018

Accepted June 28, 2018 